\title{
Purification of Single-Wall Carbon Nanotubes by Heat Treatment and Supercritical Extraction
}

\author{
Mariana Bertoncini ${ }^{a}$, Luiz Antonio Ferreira Coelho ${ }^{a}$, \\ Indhira Oliveira Maciel ${ }^{\mathrm{b}, \mathrm{c}}$, Sérgio Henrique Pezzin ${ }^{\text {a* }}$ \\ ${ }^{a}$ Center of Technological Sciences, Santa Catarina State University - UDESC, \\ Campus Universitário s/n, CEP 89223-100, Joinville, SC, Brazil \\ ${ }^{\mathrm{b}}$ Materials Department, National Institute of Metrology - INMETRO, \\ CEP 25250-020, Duque de Caxias, RJ, Brazil \\ 'Department of Physics, Federal University of Juiz de Fora - UFJF, \\ Campus Universitário, CEP 36036-900, Juiz de Fora, MG, Brazil
}

Received: March 21, 2011; Revised: July 8, 2011

\begin{abstract}
Arc discharge is the most practical method for the synthesis of single wall carbon nanotubes (SWCNT). However, the production of SWCNT by this technique has low selectivity and yield, requiring further purification steps. This work is a study of purification of SWCNT by heat treatment in an inert atmosphere followed by supercritical fluid extraction. The raw arc discharge material was first heat-treated at $1250{ }^{\circ} \mathrm{C}$ under argon. The nanotubes were further submitted to an extraction process using supercritical $\mathrm{CO}_{2}$ as solvent. A surfactant (tributylphosphate, TBP) and a chelating agent (hexafluoroacetylacetone, HFA) were used together to eliminate metallic impurities from the remaining arc discharge catalysts. Analysis of Inductively Coupled Plasma-Atomic Emission Spectrometry (ICP-AES) showed an efficient removal of iron and cobalt ( $>80 \%)$. The purified nanotubes were further analyzed by TGA and Raman spectroscopy.
\end{abstract}

Keywords: single-wall carbon nanotubes, purification, extraction, supercritical fluid

\section{Introduction}

Several techniques have been developed for carbon nanotube synthesis such as arc discharge, chemical vapour deposition (CVD) and laser ablation ${ }^{1-2}$. Arc discharge is the most practical method of single wall carbon nanotube (SWCNT) synthesis, producing nanotubes with fewer structural defects than those produced by low temperature techniques ${ }^{2}$. However, the production of SWCNT by this technique has, in general, low selectivity and yield, requiring further purification steps. The purification of carbon nanotubes (CNT) is becoming specific and, with the developments in synthesis methods, fewer residues are formed. Part of this evolution is linked to the addition of metal catalysts to improve the synthesis performance. Thus, the impurities in SWCNT typically are amorphous carbon and transition metals, like iron, nickel and cobalt, used as catalysts in the preparation and the growth of the CNT.

A variety of purification methods have been developed; however, removing impurities with high selectivity has been challenging ${ }^{3,4}$. Most of the purification methods involve gas phase oxidation at elevated temperatures $\left(300-800{ }^{\circ} \mathrm{C}\right)$, or wet chemical oxidation with nitric acid, $\mathrm{H}_{2} \mathrm{O}_{2}$, or $\mathrm{KMnO}_{4}^{4}$. These aggressive processes can damage SWCNT severely ${ }^{3,5}$. Heating the metal impurities with microwaves or submitting CNT to metal-catalyzed oxidation have been also used to improve the carbon yield and purity ${ }^{3}$, but highly selective and environmentally friendly purification approaches have yet to be developed. For some applications of CNTs, such as their use as bio-materials, complete removal of metal particles is of particular importance. Therefore, a number of researchers have been investigating different forms to extract metals from CNT, including the use of supercritical fluid $(\mathrm{SCF})^{6}$.
Despite the large number of studies on the behavior of organic compounds in supercritical fluids, there is little information about its use in the extraction of metals from aqueous media. The use of $\mathrm{CO}_{2}$ as SCF for the direct extraction is inefficient due to their weak interaction with the metal and, therefore, inability to neutralize its charge. The complexation with appropriate ligands seems a good solution, as the complexed metal ion have an increased solubility in supercritical $\mathrm{CO}_{2}$. The complexing agents must have high stability constants at low $\mathrm{pH}$, high solubility in the SF and fast kinetics of complexation?

The extraction of metal ions in the aqueous phase by chelating agents can occur by the formation of extractable complexes such as $\beta$-diketonates and organophosphates. Tributylphosphate (TBP), for example, has long been established for use as extractive ligand for metal ions ${ }^{8}$. Some combinations of two extraction agents can cause a large increase in the amount of metal extracted, acting synergistically ${ }^{9}$. Therefore, the use of two extractants (usually a surfactant and a chelating agent) in combination can potentially enhance the extraction of metals from CNT in an acidic media ${ }^{6}$.

To facilitate the process of extracting metals, it is interesting to add a purification step to expose carbon-enwrapped metal particles. Heat treatment until $1800{ }^{\circ} \mathrm{C}$ in inert atmosphere, for example, can change the structure of the CNT, eliminating defects, and can also assist in the removal of metals from catalysts ${ }^{10}$.

In this work the purification of SWCNT by heat treatment in an inert atmosphere followed by extraction of metals in supercritical $\mathrm{CO}_{2}$, assisted by TBP and HFA, has been studied. The nanotubes 
were characterized before and after purification by thermogravimetric analysis (TGA) and Raman spectroscopy.

\section{Materials and Methods}

Single wall carbon nanotubes (SWCNT) used in this study were purchased from the Laboratory of Nanomaterials - Federal University of Minas Gerais (UFMG, Brazil). These nanotubes were produced by the method of electric arc discharge and had a purity level of $40 \%$ (amorphous carbon, $\mathrm{Co}, \mathrm{Ni}$ and $\mathrm{Fe}$ as main impurities).

65\% nitric acid (Merck), tributylphosphate (TBP) PA (Sigma Aldrich) and hexafluoroacetylacetone (HFA) PA (Sigma Aldrich) were used as received. $\mathrm{CO}_{2}$ (Air Liquid) with a minimum purity of $99.9999 \%$ was used as supercritical fluid.

\subsection{Heat treatment}

SWCNT were placed in a porcelain container and heated up to $1250{ }^{\circ} \mathrm{C}$ at $10{ }^{\circ} \mathrm{C} / \mathrm{min}$ in a TCR 50 sintering furnace with MicroCOR III controller (Adamel Lhomargy). The system was maintained at $1250{ }^{\circ} \mathrm{C}$ for 4 hours and then cooled at $10{ }^{\circ} \mathrm{C} / \mathrm{min}$ to room temperature. The material was carefully weighed and characterized by TGA and Raman spectroscopy.

\subsection{Supercritical fluid apparatus}

In this work, we studied static and dynamic extraction of metals from SWCNT, with the aid of TBP and HFA as complexing agents. Figure 1 shows a schematic diagram of the apparatus assembled and used for carrying out the procedures cited in this article. The equipment consists of a stainless steel high-pressure cell with a variable volume (1); a magnetic stirrer, IKA (2); a thermostatic water bath, Cientec CT 281 (3); a jacketed high pressure syringe-type pump, ISCO 500D (4), a thermostatic jacket for the high pressure cell with a Switron RWMC-7 temperature controller (5); a light source (6); a piston to control the cell volume (7); side (8) and frontal (9) sapphire windows; a pressure transducer, SMAR 400D LD (10); a fraction collector (11) and a $\mathrm{CO}_{2}$ cylinder (12).

\subsection{Extraction of metals}

Initially, $5 \mathrm{~mL}$ of TBP were mixed with $5 \mathrm{~mL}$ nitric acid in a test tube with lid, and stirred for 4 minutes to produce the $\mathrm{CO}_{2}$-soluble TBP- $\left(\mathrm{HNO}_{3}\right)_{1.8}\left(\mathrm{H}_{2} \mathrm{O}\right)_{0.6}$ complex ${ }^{6}$. The system was then allowed to rest until there was a phase separation. Three $\mathrm{mL}$ of the supernatant were then withdrawn and transferred to a $10 \mathrm{~mL}$ beaker. $0.01 \mathrm{~g}$ of previously heat-treated single-wall nanotubes were added to the TBP- $\mathrm{HNO}_{3}$ system and sonicated for 10 minutes at $150 \mathrm{~W}$. This mixture was transferred to the cell of the supercritical fluid equipment and $0.2 \mathrm{ml}$ of HFA was added to the system. The cell was closed, heated to $60 \pm 1{ }^{\circ} \mathrm{C}$, and then filled with $25 \mathrm{~mL}$ of $\mathrm{CO}_{2}$ at $200 \mathrm{bar}$ and $5 \pm 1{ }^{\circ} \mathrm{C}$. The system was maintained under magnetic stirring at this pressure and temperature of $60 \pm 1{ }^{\circ} \mathrm{C}$ for 1.5 hours. The system was then slowly depressurized with the aid of a micrometer needle valve (Autoclave Engineers, 10VRMM2812) for 1 hour. At the end of the procedure, the cell was cooled down to room temperature and the SWCNT were flushed out of the cell with deionized water (type 2). The extracted nanotubes were filtered using a PVDF filter (PALL, pore size of $0.45 \mu \mathrm{m}$ ), washed with deionized water, and dried at $80{ }^{\circ} \mathrm{C}$ for 24 hours. The material was then carefully weighed and characterized by Raman, TG and ICP-AES.

\subsection{Characterization}

For Raman measurements a Jobin Yvon T64000 triple spectrometer was used in backscattering configuration, with a $514.5 \mathrm{~nm}$ excitation laser wavelength. SWCNT samples were analyzed in at least four different points in the range from 100 to $300 \mathrm{~cm}^{-1}$ and 1200 to $1750 \mathrm{~cm}^{-1}$. Quantitative analysis of metals was performed using an inductively coupled plasma - atomic emission spectrometer (ICP-AES), iCAP 6000 (Thermo Scientific). Thermogravimetric analyses (TGA) were performed on a Netzsch STA 449C equipment starting from the ambient temperature to $650{ }^{\circ} \mathrm{C}$ at $10{ }^{\circ} \mathrm{C} / \mathrm{min}$ in oxidizing atmosphere (synthetic air).

\section{Results and Discussion}

The Raman spectra of nanotube samples before treatment, after heat treatment and after the supercritical fluid extraction of metals are shown in Figure 2 (Radial Breathing Mode, RBM, 100-300 $\mathrm{cm}^{-1}$ ) and Figure 3 (D and $\mathrm{G}$ bands, $1250-1750 \mathrm{~cm}^{-1}$ ). The position of the RBM peaks and the $\mathrm{G}$ band feature confirm the presence of SWCNT and shows that the nanotubes are mostly semiconductors ${ }^{11}$. RBM peaks are characteristic of single wall carbon nanotubes and can be used to estimate SWCNT diameter by considering their position in the spectra (Figure 2) ${ }^{12}$. For the studied pristine sample the diameter value was estimated as $1.22 \pm 0.02 \mathrm{~nm}$.

Raman spectra of all carbon materials exhibit characteristic peaks in the region between 1000 and $1800 \mathrm{~cm}^{-1}$ for excitation energy in the visible and infrared. For graphitic materials, this region is related to the D, G and D' bands, where the G band $\left(1500-1600 \mathrm{~cm}^{-1}\right)$ is a first order mode with $\mathrm{E}_{2 \mathrm{~g}}$ symmetry and the $\mathrm{D}\left(1200-1400 \mathrm{~cm}^{-1}\right)$ and D' (1600-1630 $\left.\mathrm{cm}^{-1}\right)$ bands arise due to double resonance Raman

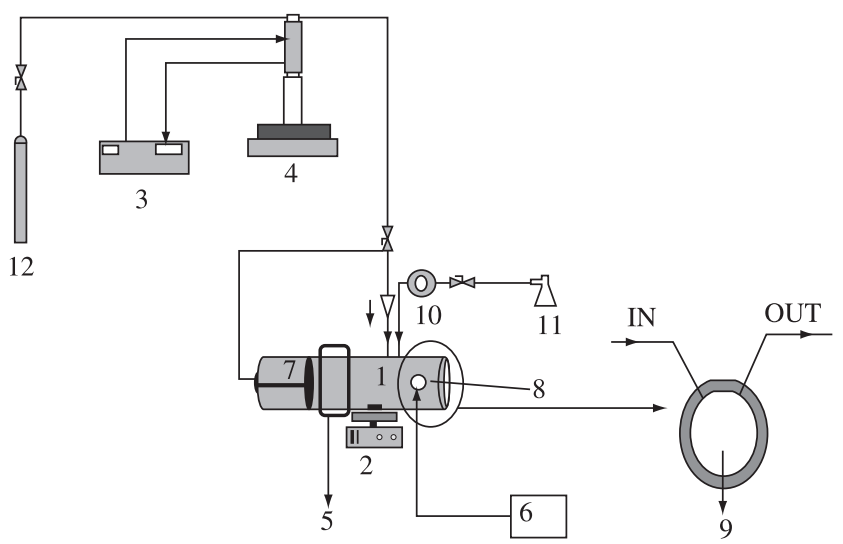

Figure 1. Schematic diagram of the supercritical fluid apparatus.

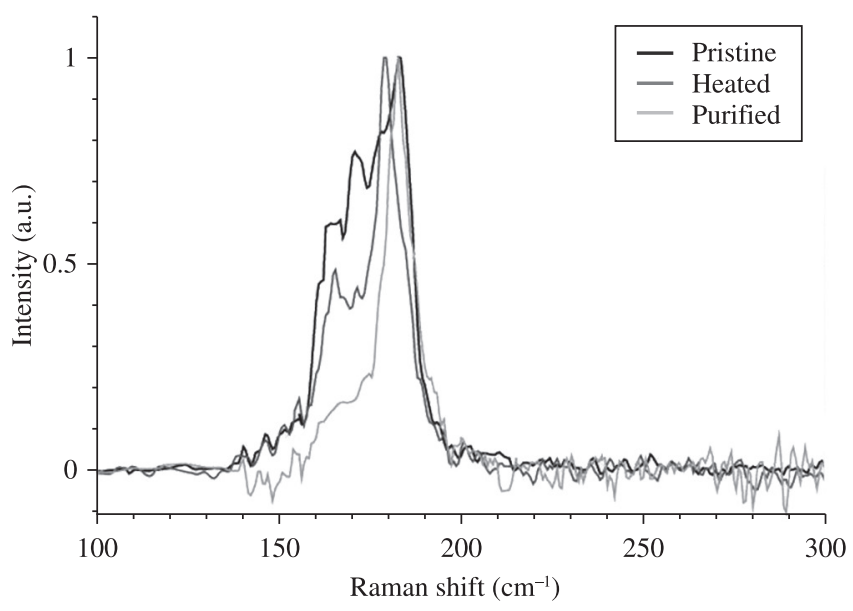

Figure 2. Raman Spectroscopy in the region of Radial Breathing Mode: pristine, heat-treated, and purified (extracted) samples. 


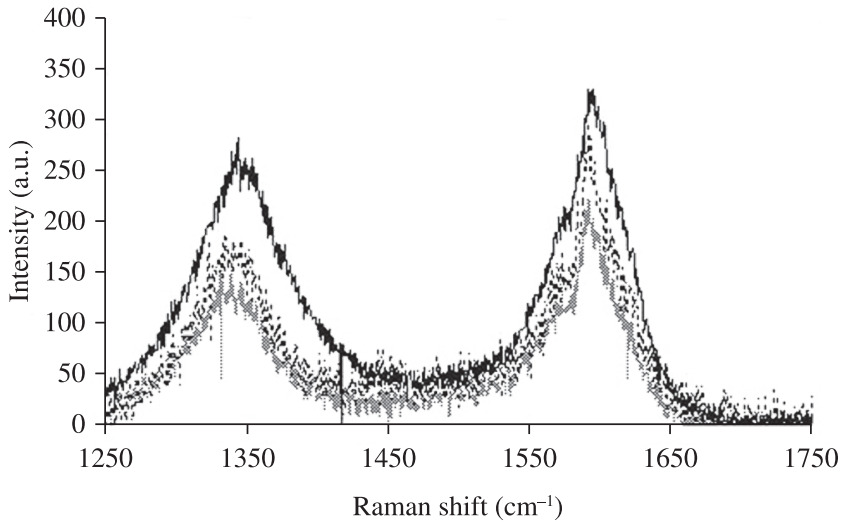

Figure 3. Raman Spectroscopy in the region of D and G bands: pristine (gray), heat treated (dotted) and SCF-extracted (black) samples.

Table 1. Raman Spectroscopy relative peak areas of $\mathrm{D}$ and $\mathrm{G}$ bands for pristine and treated samples.

\begin{tabular}{lccc}
\hline \multicolumn{1}{c}{ Sample } & $\mathrm{D}$ band $\left(\times 10^{3}\right)$ & $\mathrm{G}$ band $\left(\times 10^{3}\right)$ & \multicolumn{1}{c}{$\mathrm{G} / \mathrm{D}$} \\
\hline Pristine & $6.6 \pm 3.6$ & $10.4 \pm 5.3$ & $1,6 \pm 0,1$ \\
Heat-treated & $7.6 \pm 1.9$ & $9.1 \pm 2.8$ & $1,2 \pm 0,2$ \\
SCF-extracted & $19.9 \pm 4.0$ & $24.1 \pm 6.5$ & $1,2 \pm 0,1$ \\
\hline
\end{tabular}

processes ${ }^{13}$. Analyses of the Raman spectra show no significant change between the ratios of the peak areas of the $G$ and $D$ bands, as it is shown in Table 1. These results confirm that the structure of SWCNT was practically unchanged after heat treatment and metal extraction. Nevertheless, the spectra indicate a large amount of amorphous carbon in the samples, as denoted by the size of the $\mathrm{D}$ bands. The absence of D' band at ca. $1620 \mathrm{~cm}^{-1}$ shows that the material does not contain multiwall carbon nanotubes ${ }^{14}$.

The removal of metals from CNT is a difficult task and very hard to achieve only by wet techniques, such as acid washing, because most of the metal particles are enwrapped by carbon layers. Heat treatment at high temperatures $\left(>1200^{\circ} \mathrm{C}\right)$ under inert atmosphere could, at the same time, partially remove metals by vaporization and change the structure of CNT, removing structural defects and, consequently, increasing mechanical strength, thermal stability and electronic transport, for example ${ }^{4}$. Thermal annealing can also assist in the removal of metals from catalysts by unwrapping metal particles ${ }^{10}$. However, carbonaceous impurities are still present after treatment and become more difficult to remove after graphitization ${ }^{15}$. This was observed in this work, as Raman spectra have shown the same profile before and after heat treatment.

Quantitative analysis of metals by ICP-AES showed that untreated SWCNT contained $0.98 \%$ iron, $0.35 \%$ nickel and $0.88 \%$ cobalt. After heat treatment and extraction process the quantities decreased to $0.16 \%$ iron (removal of $84 \%$ of the initial metal amount), $0.32 \%$ nickel (removal of $8.6 \%$ ) and $0.16 \%$ cobalt (removal of $82 \%$ ). The results prove the efficiency of the purification process for iron and cobalt, which forms strong complexes with $\beta$-diketone chelating agents in supercritical $\mathrm{CO}_{2}{ }^{6,16}$. However, the fluorinated $\beta$-diketone (HFA) was not efficient to form nickel chelates. Considering the literature, better results for nickel removal could be probably achieved with dithiocarbamates ${ }^{17}$.

In the TGA curves (Figure 4), recorded under oxidizing atmosphere, it is observed that the onset temperature of oxidation

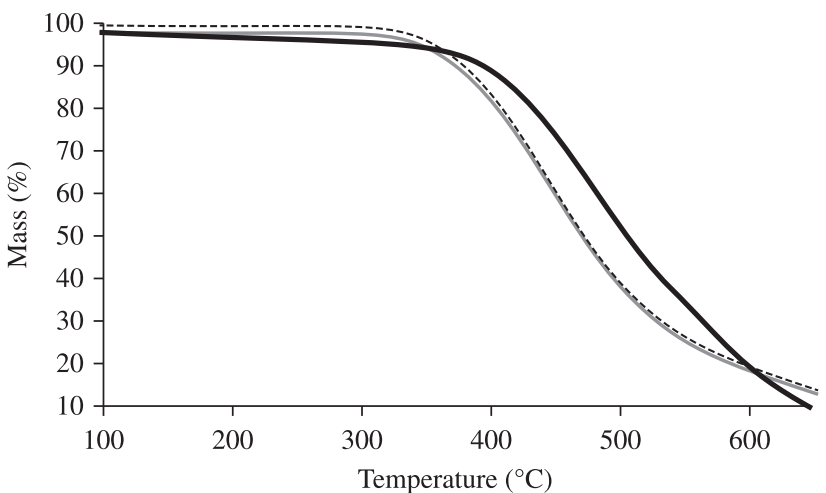

Figure 4. TGA curves in oxidizing atmosphere: pristine (gray), heat treated (dotted) and SCF-extracted (black) samples.

was lower than $400{ }^{\circ} \mathrm{C}$ for pristine and heat-treated samples. In contrast, after the extraction of metals, the temperature of initiation of degradation was considerably higher than $400^{\circ} \mathrm{C}$, showing that the presence of metal catalysts influences the oxidation temperature of CNT. It is also verified that, at $650{ }^{\circ} \mathrm{C}$, the residual mass for pristine (untreated) samples was $12 \%$ of the initial mass. The residual mass at $650{ }^{\circ} \mathrm{C}$ decreases to $9 \%$ of the initial mass for heat-treated samples and for heat-treated samples after supercritical extraction.

\section{Conclusions}

The extraction of metals using supercritical carbon dioxide combined with a pre-heat treatment under argon was effective to remove iron and cobalt from SWCNT. Raman spectroscopy suggests that the structure of the SWCNT remains intact after the purification procedure, avoiding structure damage that may result from acid treatments. Thermogravimetric analyses show that the presence of metals influence the initial temperature of oxidation of carbonaceous samples containing SWCNT.

Thus, it can be said that the heat treatment and the supercritical extraction were effective in removing some metallic impurities (namely $\mathrm{Fe}$ and $\mathrm{Co}$ ), but it was not able to remove carbonaceous impurities to a considerable extent.

\section{Acknowledgements}

The authors thank CAPES, CNPq, AEB and PGCEM-UDESC for financial and structural support.

\section{References}

1. Harris PJF. Carbon Nanotube Science: Synthesis, Properties and Applications. Cambridge: Cambridge University Press; 2009. http://dx.doi.org/10.1017/CBO9780511609701

2. Keidar M. Factors affecting synthesis of single wall carbon nanotubes in arc discharge. Journal of Physics D: Applied Physics. 2007; 40:23882393. http://dx.doi.org/10.1088/0022-3727/40/8/S18

3. Wang Y, Shan H, Hauge RH, Pasquali M and Smalley RE. A Highly Selective, One-Pot Purification Method for Single-Walled Carbon Nanotubes. Journal of Physical Chemistry B. 2007;111(6):1249-52. http://dx.doi.org/10.1021/jp068229+

4. Hou PX, Liu C and Cheng HM. Purification of carbon nanotubes. Carbon. 2008; 46(15):2003-2025. http://dx.doi.org/10.1016/j.carbon.2008.09.009

5. Hu H, Zhao B, Itkis ME and Haddon RC. Nitric Acid Purification of Single-Walled Carbon Nanotubes. Journal of Physical Chemistry B. 2003; 107(50):13838-13842. http://dx.doi.org/10.1021/jp035719i

6. Wang JS, Wai Cm, Shimizu K, Cheng F, Boeckl Jj, Maruyama B et al. Purification of Single-Walled Carbon Nanotubes Using a Supercritical 
Fluid Extraction Method. Journal of Physical Chemistry C. 2007; 111(35):13007-12. http://dx.doi.org/10.1021/jp073374o

7. Chen J, Shan JY, Tsukada T, Munekane F, Kuno A, Matsuo M et al. The structural evolution of thin multi-walled carbon nanotubes during isothermal annealing. Carbon. 2007; 45:274-280. http://dx.doi. org/10.1016/j.carbon.2006.09.028

8. Wai CM and Wang SF. Supercritical fluid extraction: metals as complexes. Journal of Chromatography A. 1997; 785(1-2):369-383. http://dx.doi. org/10.1016/S0021-9673(97)00679-1

9. Almeida VF. Separação de actinídeos utilizando-se calixarenos como agentes extratores. [Dissertação]. São Paulo: Instituto de Pesquisas Energéticas e Nucleares; 2001.

10. Rao A, Kumar P and Ramakumar KL. Separation of uranium from different uranium oxide matrices employing supercritical carbon dioxide extraction. Journal of Radioanalytical and Nuclear Chemistry. 2010; 285:247-257. http://dx.doi.org/10.1007/s10967-010-0568-7

11. Kataura H, Kumazawa Y, Maniwa Y, Umezu I, Suzuki V, Ohtsuka Y et al. Optical properties of single-wall carbon nanotubes. Synthetic Metals. 1999; 103:2555-2558. http://dx.doi.org/10.1016/S0379-6779(98)00278-1
12. Jorio A, Pimenta MA, Souza Filho AG, Saito R, Dresselhaus G and Dresselhaus MS. Characterizing carbon nanotube samples with resonance Raman scattering. New Journal of Physics. 2003; 5:139.1-139.17.

13. Lobo AO, Martin AA, Antunes EF, Trava-Airoldi VJ and Corat EJ. Caracterização de Materiais Carbonosos por Espectroscopia Raman. Revista Brasileira de Aplicações de Vácuo. 2005; 24:98-103.

14. Strong KL, Anderson DP, Lafdi K and Kuhn JN. Purification process for single-wall carbon nanotubes. Carbon. 2003; 41(8):1477-1488. http://dx.doi.org/10.1016/S0008-6223(03)00014-9

15. Andrews R, Jacques D, Qian D and Dickey EC. Purification and structural annealing of multiwalled carbon nanotubes at graphitization temperatures. Carbon. 2001; 39:1681-1687.

16. Wang JS and Wai CM. Dissolution of Precious Metals in Supercritical Carbon Dioxide Industrial \& Engineering Chemistry Research. 2005; 44:922-926. http://dx.doi.org/10.1021/ie040198m

17. Ashraf-Khorassani M, Combs MT and Taylor LT. Solubility of metal chelates and their extraction from an aqueous environment via supercritical $\mathrm{CO}_{2}$. Talanta. 1997; 44(5):755-763. http://dx.doi.org/10.1016/S00399140(96)02075-9 